\title{
8-WEEK TRAINING IN PARTIAL MINIMALIST SHOE REDUCES IMPACT FORCE DURING RUNNING
}

original paper

( ) University School of Physical Education in Wroclaw

DOI: https://doi.org/10.5114/hm.2018.77320

\section{ANA P.S. AZEVEDO, BRUNO MEZENCIO, LUIS MOCHIZUKI, RAISA VALVASSORI, ALBERTO C. AMADIO, JULIO C. SERRAO}

Laboratory of Biomechanics, School of Physical Education and Sport, University of São Paulo, São Paulo, Brazil

\begin{abstract}
Purpose. Excessive external load is a likely cause of running injuries. Although minimal running has been suggested as a possible approach to reduce impact and injury risk, an abrupt transition from conventional shoes to minimal running is also related to injuries. Therefore, the partial minimalist shoe has been suggested as a training strategy for a safe transition to minimal running. The study investigated if 8 weeks of training in partial minimalist shoe could improve impact control of shod and barefoot running.

Methods. Recreational runners (12 men, 2 women), inexperienced in minimal running, performed 3 training sessions/week in partial minimalist shoes for 8 weeks. Before and after the intervention, the participants ran on a treadmill at $2.5 \mathrm{~m} / \mathrm{s}$ under two conditions: in their habitual shoes and barefoot. Vertical ground reaction force (VGRF) was recorded.

Results. After the intervention, reduced values of the first peak ( $16.7 \%$ for shod, $36.7 \%$ for barefoot), time to reach the first peak (7.7\% for shod, $30.2 \%$ for barefoot), and the load rate of the first peak ( $9.8 \%$ for shod, $9.5 \%$ for barefoot) were observed for both conditions $(p<0.001)$. Six subjects dropped out from the intervention.

Conclusions. Partial minimalist training improved VGRF variables related to shock attenuation. Thus, the 8-week running training program with partial minimalist shoes was an effective approach to increase impact control. The intervention reduced the impact force in both shod and barefoot running, arising as a feasible option to progressively transition to minimal running. Key words: biomechanics, ground reaction force, shock attenuation, barefoot, transition
\end{abstract}

\section{Introduction}

High injury incidence in running still causes concern [1-5]. Repeated external load is a likely cause of running injuries [5-9]. The vertical ground reaction force (VGRF) is one of the most representative parameters of external load in movement and represents the impact force received by the human body during locomotion. The force is generated by a shock (or collision) between foot and ground [10]. Although the relationship between injury and VGRF is complex and still unclear, high magnitudes of impact force and its repeated transmission along the body have been reported as some possible causes of pain, degenerative musculoskeletal diseases, and running-related injuries [9, 11, 12]. Recently, barefoot training has been suggested as a pos- sible approach to reduce these injuries [7, 13-15]. An important benefit elicited by barefoot running seems to be improvements in VGRF related to impact, e.g. reduced impact peak and loading rate [7, 13].

Nevertheless, the tolerance of the plantar surface (e.g. tolerance of skin to abrasion and sharp objects) possibly limits the mileage in barefoot running, mainly in novice minimal runners [16]. Minimalist shoes were developed to simulate barefoot running while protecting the plantar surface. Therefore, the minimalist shoe has been reported to be the main path to promote minimalist running (i.e. running in minimalist shoes or barefoot) and to transition to barefoot running in recent years [17].

Evidence indicates that running in minimalist shoe can be an effective strategy to simulate barefoot running

Correspondence address: Ana Paula da Silva Azevedo, 65 Professor Melo Moraes Avenue, Butantã, São Paulo, 05508-030, Brazil, e-mail: anaazevedo@usp.br

Received: November 5, 2017

Accepted for publication: April 30, 2018

Citation: Azevedo APS, Mezencio B, Mochizuki L, Valvassori R, Amadido AC, Serrao JC. 8-week training in partial minimalist shoe reduces impact force during running. Hum Mov. 2018;19(4):20-28; doi: https://doi.org/10.5114/hm.2018.77320. 
$[15,18]$, to modify biomechanical characteristics of running [19-22], and to encourage positive adaptations in the human structures $[7,8,23]$. Such changes seem to improve parameters related to shock attenuation and performance, and might facilitate a safe and appropriate transition to barefoot running [7, 23-25]. Warne et al. [25] observed reduced plantar pressure after 4 weeks of running in minimalist shoes. The size of intrinsic muscles of the foot increased after a 10-week period in minimalist shoes [23]. After 12 weeks of simulated barefoot running, McCarthy et al. [24] revealed kinematic parameters similar to barefoot and higher preference for a forefoot strike pattern.

However, other evidence suggests that minimalist shoes have no influence on or increase injury risk [26-29]. Previous studies reported increased impact forces [30], peak of plantar pressure [31], and joint power [32-35] during running under these conditions. Additionally, stress fractures have been observed in minimalist runners [3, 36-38].

Case reports indicate that injuries in minimalist running are related to an abrupt transition from conventional to minimalist shoes [36-38]. Therefore, the way that transition is done must be considered by runners and seems to be an important factor to achieve minimal running safely. There are different transition methods and the best outcomes likely result from an interaction between several factors, such as running experience, exposure to minimalist shoes, and length of the transition period [39]. Considering the wide variety of minimalist footwear, a possible and practical way of transitioning could be through different levels of minimalist shoes.

Self-described 'minimalist shoes' are offered by multiple footwear manufacturers. Minimalist shoes typically present reduced cushioning, lower heel height, lower heel-forefoot offset; they are highly flexible and lighter than conventional shoes, and have no stabilizing devices [40]. Nevertheless, minimalist shoes can vary in design characteristics from very minimalistic to more structured and partial minimalist shoes [18]. The partial minimalist shoes have many characteristics of minimalist shoes but less pronounced, and they are classified as distinct from minimalist and conventional shoes. Considering that different models of minimalist footwear seem to target different aspects of 'barefoot' running style and influence runners in various ways [18], manufacturers have suggested partial minimalist shoes as a possible training tool to induce primary adaptations to minimalist running and to transition progressively and cautiously adopt minimalist shoes and/or barefoot condition.
To the best of our knowledge, few researches have investigated the use of minimalist or partial minimalist shoes as a training approach. Despite impact forces and their manipulation (e.g. through different footwear and surfaces) have been reported as possible causes of injuries in running $[2,5,6,9]$, no study has focused on how the adoption of partial minimalist shoes as a training approach could manipulate shock attenuation and mechanical load parameters of shod and barefoot running. As far as we know, there is still no sufficient theoretical basis to fully encourage the adoption of minimalist shoes in running training to seek the reduction of external forces. Longitudinal research concerning the transition to minimal protective running remains sparse.

Thus, the purpose of this study was to investigate whether an 8-week running training program with partial minimalist shoes was an effective training approach to change VGRF parameters related to impact and improve shock attenuation in both shod and barefoot condition. Our hypothesis was that 8 weeks of running training in partial minimalist shoe would be enough to induce changes in running kinetics. It was also hypothesized that training in partial minimalist shoes would reduce impact force parameters in both shod and barefoot running.

\section{Material and methods}

\section{Subjects}

The total of 14 recreational runners (12 men and 2 women, $28.4 \pm 7.3$ years, $72.7 \pm 7.8 \mathrm{~kg}, 1.74 \pm 0.06 \mathrm{~m}$ ) without experience in running barefoot and/or in minimalist shoes, but experienced in running on treadmills (at least 6 months of experience) were recruited for the study. A questionnaire was used to collect information about age, running experience, running distance per week, foot strike pattern, and previous lower limb injuries. Participants were excluded if they had suffered from any structural injury in the previous 12 months and/or had any experience in running barefoot or with minimalist shoes. Additionally, foot strike pattern was self-reported and participants who presented a midfoot or forefoot strike pattern were excluded from the study.

\section{Intervention}

A fitted pair of partial minimalist shoes was provided to each participant. The model adopted in the study was the New Balance $890^{\circ}$ (Figure 1). The shoe model is commercially available and, in accordance with its 

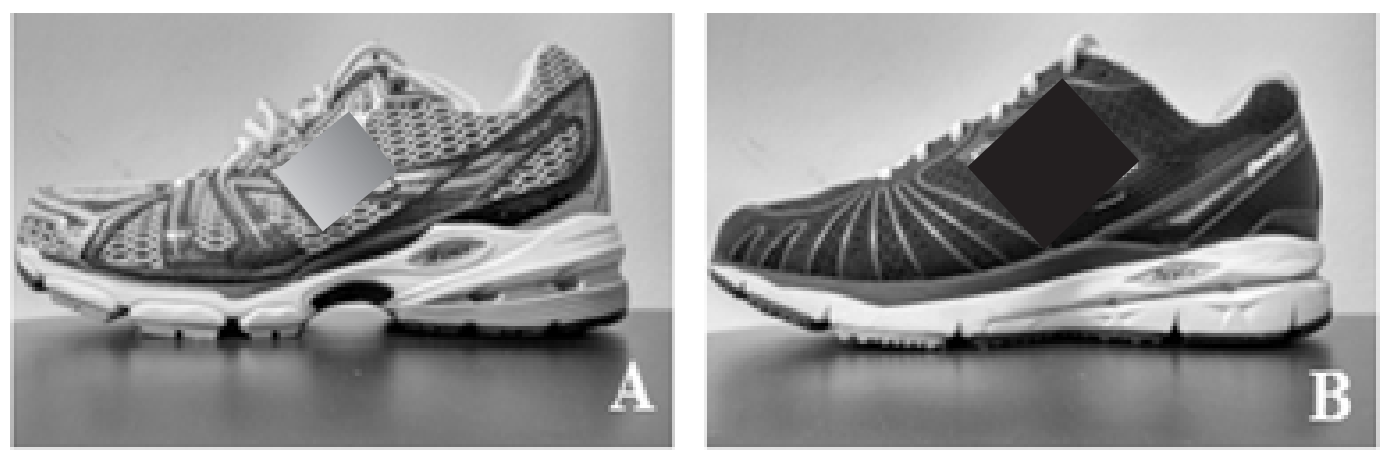

Figure 1. An example of conventional shoe worn habitually by runners (A) and the model of partial minimalist shoe adopted in the study (B)

construction characteristics, has been classified by the manufacturer as an intermediate level of minimalist shoe. The shoe chosen has lower values of absolute heel height $(40 \mathrm{~mm})$, heel-forefoot offset $(12 \mathrm{~mm})$, and weight ( $250 \mathrm{~g}$ ) when compared with average values of conventional cushioned shoes worn by the participants (absolute heel height, $45 \mathrm{~mm}$; heel-forefoot offset, $18 \mathrm{~mm}$; weight, $280 \mathrm{~g}$ ). The NB 890 have 'mesh' type upper (made of synthetic materials). Midsole uses the REVlite ${ }^{\circledast}$ technology, developed by the manufacturer, utilizing lighter viscoelastic and being 30\% lighter than conventional materials. Flexible rubber is the main material used to make the outsole. The minimalist index score (MI) of the partial minimalist shoe, calculated as suggested by Esculier et al. [40], is 40\%, which means that the shoe adopted in our study would be in an intermediary position in the spectrum of most to least minimalist.

To focus only on the shoe effect, all participants were instructed to maintain their habitual weekly running distance and training periodization. In order to meet this demand, training sessions were prepared by professionals, researchers, and participants together. All training sessions were supervised by the researchers. The participants were characterized by a minimum of 6 months of regular running training, an average weekly running distance of $88.3 \mathrm{~km}$ (range, 60-120 km), and an average weekly training volume of 4 sessions (range, 3-5 sessions). For 8 weeks, 3 training sessions of the total sessions per week planned for each runner were performed with partial minimalist shoe. In other words, the only modification was to wear the partial minimalist shoe in 3 training sessions per week, independently of the total weekly training sessions.

\section{Experimental protocol}

The participants ran, before and after intervention, at $2.5 \mathrm{~m} / \mathrm{s}$ on an instrumented treadmill under two ex- perimental conditions: barefoot and shod. The shod condition was chosen to test the intervention effectiveness because that is the way runners usually do their exercises. The unshod condition, in turn, was chosen to observe whether the possible benefits provided by the partial minimalist shoe would be extended to barefoot running. Experimental condition order was balanced to avoid learning effects.

Each session test started with participants performing a 5-minute warm-up at self-selected velocity on a treadmill. After that, they ran during 10 minutes at $2.5 \mathrm{~m} / \mathrm{s}$ on the instrumented treadmill in both barefoot and shod conditions. The runners had a 2-minute interval between each trial while the experimental condition was changed. For the shod trial, they wore their own habitual running shoes, i.e. conventional cushioned running shoes, presenting similar characteristics of materials and construction for all participants.

\section{Equipment and data acquisition}

Ground reaction force data were obtained through an instrumented treadmill (Gaitway Instrumented Treadmill System 9810S1 mounted on a Trotter Treadmill Model 685, 01-06560201 chassis) with 2 piezoelectric force plates (Kistler, Inc.) assembled on its surface. Three trials of $10 \mathrm{~s}$ were recorded (at minute 0,5 , and 10) by the Gaitway system to document the VGRF. An average of 20 steps (10 right and 10 left) were obtained in each trial acquisition. The sampling rate was set at $2.6 \mathrm{kHz}$.

\section{Data analysis}

The VGRF data were low pass filtered by a Butterworth filter ( $4^{\text {th }}$ order, $90 \mathrm{~Hz}$ cut-off frequency). The start and end of each left and right step was determined with a 30-N threshold. The VGRF was normalized by individual body weight (BW), and the time was normalized by the total support time $(0-100 \%$ of the sup- 
port, $0.1 \%$ lag). Specific mathematical routines were developed in MATLAB 2009b (MathWorks, USA) for signal processing.

The occurrence of the first peak of VGRF was checked (Figure 2) and the percentage of steps presenting the first peak was obtained. To check the occurrence of the first peak, first of all, the global maximum of the curve was located; if there was a local maximum in the curve before the global maximum, then the first one was considered the first peak. Thus, when the steps presented a clear first peak, the following variables were calculated: magnitude of the first peak (Fv1); time to the first peak ( $\mathrm{tFv} 1)$; loading rate of the first peak (vLR1), calculated by the ratio $\mathrm{Fv} 1 / \mathrm{tFv} 1$; and impulse during the first $50 \mathrm{~ms}$ of stance (Imp50), calculated from the area under the VGRF versus time curve, until $50 \mathrm{~ms}$. These variables are related to the mechanical load applied to the human body during movement $[6,7,15,41]$.

\section{Statistical analysis}

Data normal distribution was checked with the Kolmogorov-Smirnov test, while homoscedasticity was tested by the Levene test. The chi-square test was performed to verify and compare the first peak occurrence among the experimental conditions (use of footwear and moment of evaluation). For the steps in which the first peak occurred and, therefore, the VGRF variables were obtained, a factorial analysis of variance for repeated measures with 2 factors (use of footwear and moment) was performed to compare shod and unshod running, as well as the pre- and post-intervention moments. The Tukey HSD test was carried out as post hoc test. The level of significance was 5\%. The statistical analysis was performed with SAS 9.1 software (SAS Institute Inc., USA).

\section{Ethical approval}

The research related to human use has been complied with all the relevant national regulations and institutional policies, has followed the tenets of the Declaration of Helsinki, and has been approved by the authors' institutional review board or an equivalent committee.

\section{Informed consent}

Informed consent has been obtained from all individuals included in this study.

\section{Results}

Out of the 14 participants who entered the study (12 men and 2 women, $28.4 \pm 7.3$ years, $72.7 \pm 7.8 \mathrm{~kg}$, $1.74 \pm 0.06 \mathrm{~m}), 8$ runners completed the training protocol ( 6 men and 2 women, $24.5 \pm 5.2$ years, $71.0 \pm$ $7.6 \mathrm{~kg}, 1.72 \pm 0.04 \mathrm{~m})$ and were included in the final analysis. Despite the dropouts, the group baseline characteristics remained similar.

The sample represents an adherence of $57.1 \%$ to running training in partial minimalist shoe. Dropouts from the study occurred for different reasons. One participant had an accident not related to the intervention proposed and 5 runners complained of pain or incurred injuries requiring rest, physiotherapy and/or rehabilitation: 2 reported knee pain while 3 experienced pain in the anterior portion of the thigh. Four of them dropped out in the $6^{\text {th }}$ week and 2 abandoned the training in the $7^{\text {th }}$ week.

The interaction between the factors was identified and significant differences were observed $(p<0.05)$ for VGRF parameters in response to training in partial minimalist shoe (Table 1). Barefoot running showed smaller occurrence of the first peak (Fv1 occurrence)

Table 1. Mean values of the first peak occurrence and mean and standard deviation values of the VGRF variables (only for curves with a clear first peak) in both conditions (shod and barefoot), before (PRE) and after intervention (POST) $(p<0.05)$

\begin{tabular}{|c|c|c|c|c|}
\hline \multirow{2}{*}{ Variables } & \multicolumn{2}{|c|}{ PRE } & \multicolumn{2}{|c|}{ POST } \\
\hline & Shod & Barefoot & Shod & Barefoot \\
\hline Fv1 occurrence ( $\%$ of steps) $)^{a, b, c, d}$ & $81.49 \%$ & $50.76 \%$ & $90.09 \%$ & $45.97 \%$ \\
\hline Fv1 $(B W)^{a, b, d}$ & $1.50 \pm 0.03$ & $1.50 \pm 0.03$ & $1.25 \pm 0.03$ & $0.95 \pm 0.05$ \\
\hline $\mathrm{tFv1}(\mathrm{ms})^{\mathrm{a}, \mathrm{b}, \mathrm{c}, \mathrm{d}}$ & $40.77 \pm 1.11$ & $21.62 \pm 1.34$ & $37.64 \pm 1.10$ & $15.09 \pm 1.15$ \\
\hline $\operatorname{vLR} 1(\mathrm{BW} / \mathrm{s})^{\mathrm{a}, \mathrm{b}, \mathrm{c}, \mathrm{d}}$ & $36.81 \pm 0.98$ & $69.80 \pm 3.55$ & $33.19 \pm 0.83$ & $63.15 \pm 3.52$ \\
\hline Imp50 (BW·s) & $356.00 \pm 1.74$ & $372.00 \pm 1.74$ & $339.00 \pm 1.74$ & $329.00 \pm 1.74$ \\
\hline
\end{tabular}

Fv1 - magnitude of the first peak, BW - body weight, $\mathrm{tFv1}$ - time to the first peak, vLR1 - loading rate of the first peak, Imp50 - impulse during the first $50 \mathrm{~ms}$ of stance

${ }^{a}$ significant difference between PRE and POST for the shod condition; ${ }^{\mathrm{b}}$ significant difference between PRE and POST for the barefoot condition; ${ }^{\mathrm{c}}$ significant difference between shod and barefoot in PRE; ${ }^{\mathrm{d}}$ significant difference between shod and barefoot in POST 
A.P.S. Azevedo et al., Minimalist training reduces impact force

compared with shod running $(p<0.001)$. Shod running revealed higher $(p<0.001)$ occurrence of the first peak after intervention, while barefoot running had smaller $(p<0.001)$ first peak occurrence after intervention.

For the steps presenting the first impact peak, differences were found $(p<0.05)$ for all VGRF variables between pre- (PRE) and post-intervention (POST), except for Imp50. In shod condition, the intensity of Fv1 was different between PRE and POST, being 16.7\% smaller in POST $(p<0.001$; mean difference \pm confidence interval [CI], $0.25 \pm 0.08 \mathrm{BW})$. Similarly, tFv1 and vLR1 showed reduced values after the intervention for shod condition, being 7.7\% $(p<0.001$; mean difference \pm CI, $3.13 \pm 3.06 \mathrm{~ms})$ and $9.8 \%(p<0.001$; mean difference $\pm \mathrm{CI}, 3.62 \pm 2.51 \mathrm{BW} / \mathrm{s}$ ) smaller in POST, respectively. For barefoot, there was a decrease of about $36.7 \%$ in Fv1 ( $p<0.001$; mean difference \pm CI, $0.55 \pm 0.11 \mathrm{BW})$, of $30.2 \%$ in tFv1 ( $p<0.001$; mean difference \pm CI, $6.53 \pm 3.46 \mathrm{~ms}$ ), and of $9.5 \%$ in vLR1 $(p<0.001$; mean difference \pm CI, $6.65 \pm 9.80 \mathrm{BW} / \mathrm{s})$ for POST compared with PRE.

The tFv1 was different between shod and barefoot in PRE and in POST (Table 1), being 47.0\% ( $p<0.001$; mean difference \pm CI, $19.15 \pm 3.41 \mathrm{~ms})$ and $59.9 \%(p<$ 0.001 ; mean difference \pm CI, $19.15 \pm 3.41 \mathrm{~ms}$ ) smaller for barefoot, respectively. In contrast, barefoot showed higher values of vLR1 in PRE (89.6\%) ( $p<0.001$ : mean

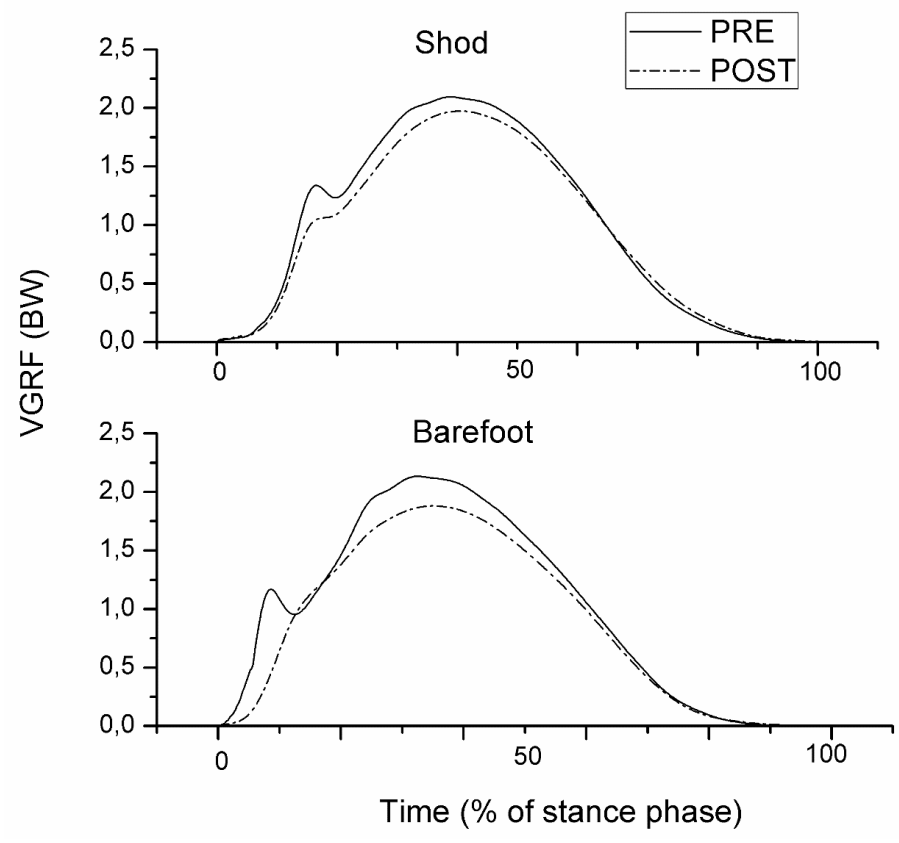

VGRF - vertical ground reaction force, BW - body weight

Figure 2. Illustrative mean VGRF curves (considering only steps with the first peak) for one participant during running shod and barefoot, in both moments (PRE and POST intervention) difference $\pm \mathrm{CI},-32.99 \pm 7.22 \mathrm{BW} / \mathrm{s})$ and in POST $(90.3 \%)(p<0.001$; mean difference \pm CI, $-29.96 \pm$ $7.09 \mathrm{BW} / \mathrm{s})$ when compared with the shod condition $(p<0.001)$. In PRE, there was no significant difference in Fv1 between the shod and barefoot conditions, whereas the shod condition showed an Fv1 31.6\% higher ( $p<$ 0.001 ; mean difference \pm CI, $0.40 \pm 0.11 \mathrm{BW}$ ) than the barefoot condition in POST. Illustrative mean VGRF curves (considering only steps with the first peak) obtained for one participant during shod and barefoot running before and after intervention are presented in Figure 2.

\section{Discussion}

The study aimed to investigate whether an 8-week running training program with a commercially available partial minimalist shoe was an effective training approach to change VGRF parameters related to shock attenuation and impact force control. To the best of our knowledge, this is the first study to examine the effects of training in partial minimalist shoe on shod and barefoot running kinetics.

The main finding of the study was that even a structured minimalist shoe $(\mathrm{MI}=40 \%)$ was enough to elicit changes in VGRF parameters in the 8-week training. Important biomechanical variables related to impact regulation, such as Fv1, tFv1, and vLR1, were influenced by the 8 -week running training in partial minimalist shoe. The results are similar to those reported in other studies for very minimalistic shoes $[7,15$, 25]. Additionally, training in partial minimalist shoe changed the frequency of Fv1 occurrence for barefoot, which corroborates the literature [7, 15, 42]. Such results denote that 8 weeks of running training with partial minimalist shoe is able to manipulate the impact load control.

The fact that changes occurred not only during barefoot running, but also during shod running is important to highlight. Barefoot running showed decreased Fv1 and vLR1 after intervention. Barefoot first peak occurrence also reduced from PRE to POST, probably as a consequence of the intervention. These results suggest that the training in partial minimalist shoe improved the impact load control in barefoot running, corroborating other studies [7, 13, 15, 33], which found disappearance of the first VGRF peak in this mechanical condition. Also, the results are in line with those achieved by Lieberman et al. [7] and Squadrone and Gallozzi [15], who reported reduced Fv1 and vLR1 in habitual barefoot runners. On the contrary, the shod running condition increased the first peak occurrence 
in POST, indicating a possibly detrimental influence on shod running. However, the reduced Fv1 and vLR1 in POST suggest changes in running kinetics and decreased impact force for this condition. It means that, despite the higher number of steps presenting the first peak, a decreased impact was observed for them, compensating the higher Fv1 occurrence. Such results suggest an improved impact regulation for shod running as a consequence of training in partial minimalist shoe. These outcomes remain in line with the studies by Warne et al. [25] and Lieberman et al. [7], who reported alterations in external forces and reduced Fv1 after minimalist training in habitual shod runners. The importance of these results is that a reduced impact force may be a relevant factor to reduce the risk of injury, mainly in exercises in which this force is applied repetitively to the body (e.g. running) [9, 43, 44]. Thus, running in partial minimalist shoe seems to be a useful training approach to improve shock attenuation, to reduce impact, and to prevent injuries in both shod and barefoot conditions. Additionally, our results seem to support the adoption of this training strategy to mediate the transition from conventional shoe to minimal running.

Shod and barefoot running presented distinct impact regulation before intervention. The smaller $\mathrm{tFv} 1$ and the higher vLR1 during barefoot running, as expected for habitual shod runners [7, 15, 33, 42], may indicate a less efficient impact regulation and higher mechanical load for this condition before intervention. However, the smaller occurrence of the first VGRF peak for barefoot suggests adaptive responses to this condition even before intervention. After intervention, Fv1 and the first peak occurrence were smaller in barefoot compared with shod running, which is in line with literature [7, 15, 25, 33, 42]. These results suggest that the chronic adaptations to the 8 weeks of running training in partial minimalist shoe seem to be larger in barefoot running and reinforce the possibility of improvements in impact regulation. Considering that a minimalist shoe is expected to provide a mechanical condition different from conventional shoe and closer to barefoot $[7,15,18]$, barefoot running might be more sensitive to partial minimalist shoe training than shod running. Another hypothesis could be that the stimulus offered by our partial minimalist shoe could take more than 8 weeks to show more observable adaptations in shod running. McCarthy et al. [24] observed changes after 12 weeks of running training with minimalist shoes in recreational runners without experience in minimal running. Recently, Squadrone et al. [18] revealed that heel foot strikers altered spatiotempo- ral and kinematic parameters as response to minimalist shoes compared with barefoot and standard cushioning shoes. Additionally, the authors reported that the magnitude of these acute adaptations varied across the different types of minimalist shoe models.

Five runners dropped out from the study because of injuries or pain in lower limbs. Since there are studies associating the use of minimalist shoes to running injuries [26, 28, 29], the dropouts observed can be a consequence of the intervention proposed. Despite this, these injuries and pain could also be caused by a high volume of training. All runners who dropped out had a moderate to high running mileage and practiced swimming and cycling, too. Another point that must be highlighted is that running is a form of exercise with high incidence of injuries. Therefore, the 5 injuries attributable to running could simply reflect the high incidence of running injuries reported in other studies $[4,5,45]$. The real causes of these injuries are still unclear and cannot be described. However, it is acknowledged that the sample size restricts interpretation of injury data. Another point to be considered is that fear of injuries is the most prevalent perceived barrier in transitioning to minimal running [17]. Rothschild [17] revealed that many people were still afraid of getting injured for adopting minimalist shoes or barefoot condition. This feeling may influence the runners' perception of and, consequently, their decision to adhere or not to a partial minimalist running program. Such factor must be accounted for when analysing the adherence in running programs based on this training approach. Nevertheless, the adherence to partial minimalist shoe training found in our study seems to be in accordance with literature. As far as we know, only McCarthy et al. [24] investigated long-term effects of minimalist shoe familiarization and reported the dropouts. They observed $36.7 \%$ of dropouts, while our study presented $42.9 \%$. Our result is also in line with the $20-80 \%$ of absence/running injury incidence reported in literature [5, 45, 46], although these data resulted from studies with longer periods (more than 6 months) than the present study (8 weeks). In addition, the results suggest that the dropouts in the present study are in accordance with those found by other supervised exercise programs. The typical dropout rate from different types of supervised exercise programs described in literature is around 50\% [47-52], although other reasons for dropouts, beyond injuries and pain, are reported in these programs. Nevertheless, our results also corroborate studies that revealed dropouts and injuries associated to the use of minimalist shoes [26, 28, 29]. An intrinsic intervention factor that may 
A.P.S. Azevedo et al., Minimalist training reduces impact force

have contributed to the dropouts was the adoption of the partial minimalist shoe without changes in relevant training variables, e.g. running distance and intensity. Although the minimalist shoe used did not have a high MI, the lower degree of minimalism may still require a longer and more gradual transition period to improve safety.

Some limitations of this study must be considered. Running tests were performed on instrumented treadmills, which can differ from fixed ground [53, 54]. To minimize this limitation, only runners with experience in treadmills were recruited for the study. The small sample size that completed the study protocol also restricts the interpretation of results. Surface is another important factor to be mentioned. Literature reports that running surface influences external forces and mechanical load [55]. Our runners trained on asphalt (streets) and treadmill predominantly, even when wearing partial minimalist shoe. Additionally, minimalist shoes can vary in design characteristics from very minimalistic to more structured shoes. Consequently, the magnitude of adaptations differs across the different types of minimalist shoe models [18]. Therefore, the results are limited to the applied model of minimalist shoe or others with similar characteristics. Finally, our outcomes are protocol-dependent and should be extrapolated to other situations carefully.

\section{Conclusions}

An 8-week running training program based on the use of partial minimalist shoes is an efficient strategy to improve parameters related to shock attenuation and impact control among recreational runners. The intervention altered the running kinetics and led to changes in variables of VGRF related to impact forces. Improvements in impact force regulation were observed in both shod and barefoot running after training. The research provides evidence that 8-week controlled running training in a more structured minimalist shoe is enough to decrease impact forces and is a feasible training approach. This supports the use of partial minimalist shoes as a training strategy to reduce external load and injury risk, as well as to transition progressively from conventional shoe to minimal running.

\section{Acknowledgements}

The authors would like to acknowledge the subjects for their contribution to the study. Also, we thank New Balance Co. from Brazil for their assistance in providing the running shoes used in the study. The research received no financial support.

\section{Disclosure statement}

No author has any financial interest or received any financial benefit from this research.

\section{Conflict of interest}

The authors state no conflict of interest.

\section{References}

1. Altman AR, Davis IS. Barefoot running: biomechanics and implications for running injuries. Curr Sports Med Rep. 2012;11(5):244-250; doi: 10.1249/ JSR.0b013e31826c9bb9.

2. Milner CE, Ferber R, Pollard CD, Hamill J, Davis IS. Biomechanical factors associated with tibial stress fracture in female runners. Med Sci Sports Exerc. 2006; 38(2):323-328; doi: 10.1249/01.mss.0000183477.75808.92.

3. Salzler MJ, Bluman EM, Noonan S, Chiodo CP, de Asla RJ. Injuries observed in minimalist runners. Foot Ankle Int. 2012;33(4):262-266; doi: 10.3113/FAI.2012. 0262.

4. Taunton JE, Ryan MB, Clement DB, McKenzie DC, Lloyd-Smith DR, Zumbo BD. A prospective study of running injuries: the Vancouver Sun Run "In Training” clinics. Br J Sports Med. 2003;37(3):239-244; doi: 10.1136/bjsm.37.3.239.

5. Van Gent RN, Siem D, van Middelkoop M, van Os AG, Bierma-Zeinstra SM, Koes BW. Incidence and determinants of lower extremity running injuries in long distance runners: a systematic review. Br J Sports Med. 2007;41(8):469-480; doi: 10.1136/bjsm.2006.033548.

6. Hreljac A. Impact and overuse injuries in runners. Med Sci Sports Exerc. 2004;36(5):845-849; doi: 10.1249/ 01.MSS.000012680366636.DD.

7. Lieberman DE, Venkadesan M, Werbel WA, Daoud AI, D'Andrea S, Davis IS, et al. Foot strike patterns and collision forces in habitually barefoot versus shod runners. Nature. 2010;463:531-535; doi: 10.1038/nature08723.

8. Robbins SE, Hanna AM. Running-related injury prevention through barefoot adaptations. Med Sci Sports Exerc. 1987;19(2):148-156; doi: 10.1249/00005768198704000-00014.

9. Zadpoor AA, Nikooyan AA. The relationship between lower-extremity stress fractures and the ground reaction force: a systematic review. Clin Biomech. 2011; 26(1):23-28; doi: 10.1016/j.clinbiomech.2010.08.005.

10. Nigg BM, Herzog W (eds.). Biomechanics of musculoskeletal system. New York: Wiley; 1994.

11. Radin EL, Ehrlich MG, Chernack R, Abernethy P, Paul IL, Rose RM. Effect of repetitive impulsive loading on the knee joints of rabbits. Clin Orthop Relat Res. 1978; 131:288-293; doi: 10.1097/00003086-197803000-00047.

12. Radin EL, Martin RB, Burr DB, Caterson B, Boyd RD, Goodwin C. Effects of mechanical loading on the tissues of the rabbit knee. J Orthop Res. 1984;2(3):221-234; doi: 10.1002/jor.1100020303. 
13. Divert C, Mornieux G, Baur H, Mayer F, Belli A. Mechanical comparison of barefoot and shod running. Int J Sports Med. 2005;26(7):593-598; doi: 10.1055/ s-2004-821327.

14. Lieberman DE. What we can learn about running from barefoot running: an evolutionary medical perspective. Exerc Sport Sci Rev. 2012;40(2):63-72; doi: 10.1097/ JES.0b013e31824ab210.

15. Squadrone R, Gallozzi C. Biomechanical and physiological comparison of barefoot and two shod conditions in experienced barefoot runners. J Sports Med Phys Fitness. 2009;49(1):6-13.

16. Altman AR, Davis IS. Prospective comparison of running injuries between shod and barefoot runners. $\mathrm{Br}$ J Sports Med. 2016;50(8):476-480; doi: 10.1136/bjsports-2014-094482.

17. Rothschild CE. Primitive running: a survey analysis of runners' interest, participation, and implementation. J Strength Cond Res. 2012;26(8):2021-2026; doi: 10.1519/JSC.0b013e31823a3c54.

18. Squadrone R, Rodano R, Hamill J, Preatoni E. Acute effect of different minimalist shoes on foot strike pattern and kinematics in rearfoot strikers during running. J Sports Sci. 2015;33(11):1196-1204; doi: 10.1080/ 02640414.2014 .989534$.

19. Hall JP, Barton C, Jones PR, Morrissey D. The biomechanical differences between barefoot and shod distance running: a systematic review and preliminary meta-analysis. Sports Med. 2013;43(12):1335-1353; doi: 10.1007/s40279-013-0084-3.

20. Murphy K, Curry EJ, Matzkin EG. Barefoot running: does it preventinjuries? Sports Med. 2013;43(11):11311138; doi: 10.1007/s40279-013-0093-2.

21. Nunns M, House C, Fallowfield J, Allsopp A, Dixon S. Biomechanical characteristics of barefoot footstrike modalities. J Biomech. 2013;46(15):2603-2610; doi: 10.1016/j.jbiomech.2013.08.009.

22. Tam N, Astephen Wilson JL, Noakes TD, Tucker R. Barefoot running: an evaluation of current hypothesis, future research and clinical applications. Br J Sports Med. 2014;48(5):349-355; doi: 10.1136/bjsports-2013092404.

23. Johnson AW, Myrer JW, Mitchell UH, Hunter I, Ridge ST. The effects of a transition to minimalist shoe running on intrinsic foot muscle size. Int J Sports Med. 2016;37(2):154-158; doi: 10.1055/s-0035-1559685.

24. McCarthy C, Fleming N, Donne B, Blanksby B. 12 weeks of simulated barefoot running changes foot-strike patterns in female runners. Int J Sports Med. 2014;35(5): 443-450; doi: 10.1055/s-0033-1353215.

25. Warne JP, Kilduff SM, Gregan BC, Nevill AM, Moran KA, Warrington GD. A 4-week instructed minimalist running transition and gait-retraining changes plantar pressure and force. Scand J Med Sci Sports. 2014; 24(6):964-973; doi: 10.1111/sms.12121.

26. Ryan M, Elashi M, Newsham-West R, Taunton J. Examining injury risk and pain perception in runners using minimalist footwear. Br J Sports Med. 2014;48(16): 1257-1262; doi: 10.1136/bjsports-2012-092061.

27. Perkins KP, Hanney WJ, Rothschild CE. The risks and benefits of running barefoot or in minimalist shoes: a systematic review. Sports Health. 2014;6(6):475480; doi: 10.1177/1941738114546846.

28. Malisoux L, Chambon N, Urhausen A, Theisen D. Influence of the heel-to-toe drop of standard cushioned running shoes on injury risk in leisure-time runners: a randomized controlled trial with 6-month followup. Am J Sports Med. 2016;44(11):2933-2940; doi: 10.1177/0363546516654690.

29. Fuller JT, Thewlis D, Buckley JD, Brown NAT, Hamill J, Tsiros MD. Body mass and weekly training distance influence the pain and injuries experienced by runners using minimalist shoes: a randomized controlled trial. Am J Sports Med. 2017;45(5):1162-1170; doi: 10.1177/0363546516682497.

30. Willy RW, Davis IS. Kinematic and kinetic comparison of running in standard and minimalist shoes. Med Sci Sports Exerc. 2014;46(2):318-323; doi: 10.1249/ MSS.0b013e3182a595d2.

31. Bergstra SA, Kluitenberg B, Dekker R, Bredeweg SW, Postema K, van den Heuvel ER, et al. Running with a minimalist shoe increases plantar pressure in the forefoot region of healthy female runners. J Sci Med Sport. 2015;18(4):463-468; doi: 10.1016/j.jsams. 2014. 06.007.

32. Perl DP, Daoud AI, Lieberman DE. Effects of footwear and strike type on running economy. Med Sci Sports Exerc. 2012;44(7):1335-1343; doi: 10.1249/MSS. 0b013e318247989e.

33. Bonacci J, Saunders PU, Hicks A, Rantalainen T, Vicenzino BG, Spratford W. Running in a minimalist and lightweight shoe is not the same as running barefoot: a biomechanical study. Br J Sports Med. 2013; 47(6):387-392; doi: 10.1136/bjsports-2012-091837.

34. Williams DSB, Green DH, Wurzinger B. Changes in lower extremity movement and power absorption during forefoot striking and barefoot running. Int J Sports Phys Ther. 2012;7(5):525-532.

35. Sinclair J. Effects of barefoot and barefoot inspired footwear on knee and ankle loading during running. Clin Biomech. 2014;29(4):395-399; doi: 10.1016/j. clinbiomech.2014.02.004.

36. Cauthon DJ, Langer P, Coniglione TC. Minimalist shoe injuries: three case reports. Foot. 2013;23(2-3):100103; doi: 10.1016/j.foot.2013.03.001.

37. Giuliani J, Masini B, Alitz C, Owens BD. Barefootsimulating footwear associated with metatarsal stress injury in 2 runners. Orthopedics. 2011;34(7):e320-e323; doi: 10.3928/01477447-20110526-25.

38. Ridge ST, Johnson AW, Mitchell UH, Hunter I, Robinson E, Rich BS, et al. Foot bone marrow edema after a 10 -wk transition to minimalist running shoes. Med Sci Sports Exerc. 2013;45(7):1363-1368; doi: 10.1249/ MSS.0b013e3182874769. 
A.P.S. Azevedo et al., Minimalist training reduces impact force

39. Warne JP, Gruber AH. Transitioning to minimal footwear: a systematic review of methods and future clinical recommendations. Sports Med Open. 2017;3(1):33; doi: 10.1186/s40798-017-0096-x.

40. Esculier J-F, Dubois B, Dionne CE, Leblond J, Roy J-S. A consensus definition and rating scale for minimalist shoes. J Foot Ankle Res. 2015;8:42; doi: 10.1186/ s13047-015-0094-5.

41. Divert C, Baur H, Mornieux G, Mayer F, Belli A. Stiffness adaptations in shod running. J Appl Biomech. 2005;21(4):311-321; doi: 10.1123/jab.21.4.311.

42. Cheung RT, Rainbow MJ. Landing pattern and vertical loading rates during first attempt of barefoot running in habitual shod runners. Hum Mov Sci. 2014;34:120127; doi: 10.1016/j.humov.2014.01.006.

43. Hreljac A. Etiology, prevention, and early intervention of overuse injuries in runners: a biomechanical perspective. Phys Med Rehabil Clin N Am. 2005;16(3): 651-667; doi: 10.1016/j.pmr.2005.02.002.

44. Nielsen RO, Buist I, Sørensen H, Lind M, Rasmussen S. Training errors and running related injuries: a systematic review. Int J Sports Phys Ther. 2012;7(1):58-75.

45. Messier SP, Legault C, Schoenlank CR, Newman JJ, Martin DF, DeVita P. Risk factors and mechanisms of knee injury in runners. Med Sci Sports Exerc. 2008; 40(11):1873-1879; doi: 10.1249/MSS.0b013e31817ed272.

46. Baquet G, van Praagh E, Berthoin S. Endurance training and aerobic fitness in young people. Sports Med. 2003;33(15):1127-1143; doi: 10.2165/00007256200333150-00004.

47. Dishman RK. Exercise adherence: its impact on public health. Champaign: Human Kinetics Books; 1988.

48. Dishman RK. Increasing and maintaining exercise and physical activity. Behav Ther. 1991;22(3):345-378; doi: 10.1016/S0005-7894(05)80371-5.

49. King AC, Taylor CB, Haskell WL, Debusk RF. Strategies for increasing early adherence to and long-term maintenance of home-based exercise training in healthy middle-aged men and women. Am J Cardiol. 1988; 61(8):628-632; doi: 10.1016/0002-9149(88)90778-3.

50. McAuley E, Lox C, Duncan TE. Long-term maintenance of exercise, self-efficacy, and physiological change in older adults. J Gerontol. 1993;48(4):P218-P224; doi: 10.1093/geronj/48.4.P218.

51. Wilbur J, Michaels Miller A, Chandler P, McDevitt J. Determinants of physical activity and adherence to a 24-week home-based walking program in African American and Caucasian women. Res Nurs Heal. 2003;26(3):213-224; doi: 10.1002/nur.10083.

52. Williams P, Lord SR. Predictors of adherence to a structured exercise program for older women. Psychol Aging. 1995;10(4):617-624; doi: 10.1037/0882-7974.10.4.617.

53. Sinclair J, Richards J, Taylor PJ, Edmundson CJ, Brooks D, Hobbs SJ. Three-dimensional kinematic comparison of treadmill and overground running. Sports Biomech. 2013;12(3):272-282; doi: 10.1080/14763141. 2012.759614 .
54. Wank V, Frick U, Schmidtbleicher D. Kinematics and electromyography of lower limb muscles in overground and treadmill running. Int J Sports Med. 1998;19(7): 455-461; doi: 10.1055/s-2007-971944.

55. Dixon SJ, Collop AC, Batt ME. Surface effects on ground reaction forces and lower extremity kinematics in running. Med Sci Sports Exerc. 2000;32(11):1919-1926; doi: 10.1097/00005768-200011000-00016. 